\title{
Entrecruces de las creencias religiosas contemporáneas en la producción de territorialidades en los municipios de Choachí y de Ubaque, Colombia"
}

\author{
Jeferson Jesid Díaz Sastre*
}

Recepción: 15 de julio de 2018 • Aprobación: 13 de agosto de 2018

\section{Resumen}

Este artículo parte de preguntarse por la reconfiguración de lo religioso en el mundo contemporáneo, para lo que propone como objetivo el análisis de la influencia de las creencias religiosas en la apropiación del territorio y la producción de territorialidades en los municipios de Choachí y Ubaque, Colombia. Para ello, y sin desconocer la preeminencia de la religión católica, se retoman igualmente las ideas de un grupo de personas que hablan desde la reactualización de la tradición muisca. La hipótesis por desarrollar es que el territorio es un registro, índice y factor de la disputa por la resignificación del pasado, en la distinción entre la memoria por lo ancestral (lo muisca) y el peso de una tradición (la religiosidad católica), mientras que la territorialidad aboga por la confluencia armoniosa (aunque conflictiva) consecuente con la producción de sentidos propios de la circulación de las creencias: en tanto que el territorio es firmeza, la territorialidad es la creencia en acto.

Palabras clave: religión, territorio, territorialidad, tradición, creencias.

Artículo de investigación resultado del Convenio Especial N.ำ 217-2017 suscrito entre el Departamento Administrativo de Ciencia, Tecnología e Innovación (Colciencias) y la Universidad de San Buenaventura de Bogotá, dentro de la Convocatoria 761 de 2016 Jóvenes Investigadores e Innovadores. Se enmarca en el proyecto de investigación "Construcción de territorios de buen vivir, Sumak Kawsay en Bogotá y Choachí, 2016-2020, adscrito al Grupo Interdisciplinario de Estudios sobre Religión, Sociedad y Política (GIERSP) de la misma universidad. Citar como: Díaz Sastre, J. J. (2019). Entrecruces de las creencias religiosas contemporáneas en la producción de territorialidades en los municipios de Choachí y de Ubaque, Colombia. Albertus Magnus, X(2), 57-83. Dor: https://doi.org/10.153322/5005413.5213.

* Universidad de San Buenaventura, Bogotá, Colombia. Orcid: http://orcid.org/00000003-1149-2621. Correo electrónico: jjdiazcp@gmail.com 


\title{
Crisscross of contemporary religious beliefs in the production of territoriality in the municipalities of Choachí and Ubaque, Colombia
}

\begin{abstract}
This article comes from questioning the reconfiguration of religion in the contemporary world, for which purpose it proposes the analysis of the influence of religious beliefs on the appropriation of territory and the production of territorialities in the municipalities of Choachi and Ubaque, Cundinamarca. For this, and without denying the pre-eminence of the Catholic religion, the ideas of a group of people who speak from the updating of the Muisca tradition are also retaken. The hypothesis to develop is that the territory is a register, index and factor of the dispute for the resignification of the past, in the distinction between the memory by the ancestral (the Muisca) and the weight of a tradition (the Catholic religiosity), while that territoriality pleads for the harmonious confluence (albeit conflictive) consistent with the production of senses proper to the circulation of beliefs: while territory is firmness, territoriality is the belief in act.
\end{abstract}

Keywords: religion, territory, territoriality, tradition, beliefs.

\section{Entrecruzes de crenças religiosas contemporâneas na produção de territorialidades nos municípios de Choachí e Ubaque, Colombia}

\section{Resumo}

O presente artigo parte por perguntar-se pela reconfiguração do religioso no mundo contemporâneo, para o qual propõe como objetivo a análise da influência das crenças religiosas na apropriação do território e na produção de territorialidades nos municípios de Choachí e Ubaque, Cundinamarca, Colômbia. Para isto, sem desconhecer a primazia da religião católica, se retomam de igual maneira as ideias de um grupo de pessoas que falam sobre a reatualização da tradição muisca. A hipótese a ser desenvolvida é a de que o território é um registro, um índice e um fator da disputa pela ressignificação do passado, na distinção entre a memória pelo ancestral (o muisca) e o peso de uma tradição (a religiosidade católica), enquanto a territorialidade advoga pela confluência harmoniosa (embora conflitiva) consequente com a produção de sentidos próprios da circulação das crenças: enquanto o território é a firmeza, a territorialidade é a crença em curso.

Palavras-chave: religião, território, territorialidade, tradição, crenças. 


\section{Introducción}

En el orden de la jurisdicción política del Estado colombiano, Choachí y Ubaque ${ }^{1}$ son dos municipios contiguos pertenecientes al departamento de Cundinamarca y la Provincia de Oriente. Desde la ciudad de Bogotá, la vía de comunicación con estos municipios atraviesa los cerros orientales en un tiempo aproximado de dos horas y media en vehículo, recorriendo 42 y $50 \mathrm{~km}$, respectivamente. Una sensación de inmensidad del territorio señalado se experimenta al participar de la caminata Bogotá-Ubaque, recorrido que abarca $35 \mathrm{~km}$, en una iniciativa que ha sido promovida desde sus comienzos por un grupo de pobladores del municipio; una perfecta ocasión para observar la cercanía de ambos municipios con los ecosistemas de páramo Cruz Verde y Chingaza.

Como iniciativa liderada por Julio Gómez, presidente y fundador del Club Los Pumas de Ubaque, la caminata inicia en 1988 con 22 personas y para su versión número treinta logró convocar más de once mil caminantes a un recorrido que inició el 27 de enero en el barrio Altamira, al sur de la ciudad de Bogotá, con un tiempo aproximado de nueve horas de trayecto, donde se encuentran de vez en cuando caminos reales, construidos durante la época colonial sobre los caminos de los pueblos indígenas que habitaban la sabana cundiboyacense. Al final de la jornada, los marchantes se entrecruzan con una peregrinación que inicia en el punto conocido como Puente Real en Ubaque, con destino hacia el Santuario de Nuestra Señora de Belén, peregrinación católica que busca imprimir un sentido particular a la caminata.

Para J. Gómez, el caminante está invitado a "llevar el sentido de rendirle un homenaje a nuestro camino y a nuestra patrona la virgencita linda de Belén", en un encuentro propiciado con el medio ambiente y la necesidad de "proteger nuestra agua, proteger todo nuestro entorno" (Club Los Pumas de Ubaque, 2017). Estos puntos son compartidos por el padre José Soto, cura de la parroquia Nuestra Señora de Belén de Ubaque, quien, en su promoción a la participación en la caminata y la festividad en honor de la virgen patrona del pueblo, extiende un mensaje de bienvenida a los caminantes recordando:

1 Según estimaciones de Pardo (1996), el territorio del municipio de Ubaque, en tiempos precolombinos del cacique Ebaque, tuvo una gran importancia por su amplia extensión, que abarcaba los actuales municipios de Guayabetal, El Calvario y San Juanito por el costado suroriental, agregándose a los límites por occidente los municipios de Fosca, de Chipaque y de Une, con el municipio de La Calera como territorio de frontera en el norte. 
El corazón de Ubaque siempre estará abierto. [Los caminantes] encontrarán no solamente el lugar sagrado en el que hace ya 270 y algo de años, casi 300, se manifestó la virgen, sino también el pueblo, una población que da muestras de esa fe. (Arquidiócesis de Bogotá, 2017)

La aparición que describe el padre José Soto resulta relevante para la comprensión de una tradición en el municipio de Ubaque. Una primera aproximación a este misterio se encuentra narrado en la Novena a Nuestra Señora de Belén, patrona de Ubaque (Arquidiócesis de Bogotá, 2006). La historia comienza con la herencia de los cuadros de Nuestra Señora del Rosario y Nuestra Señora de Belén de Bochica al padre Diego Ramos, por parte del matrimonio de Diego Sacabuche e Isabel, por la década de 1700, puntualizando en que "este [último] lienzo fue para Diego y su santa esposa, fuente abundante de dichas y bendiciones" (p. 4). En su testamento, el labriego Sacabuche nombra al padre Ramos como su albacea, quien descubre el lienzo guardado en una caja.

Cierto día manda el padre Ramos a un sirviente que mantenga sumergido aquel lienzo en un chorro de agua durante toda la noche. $\mathrm{Y}$, joh milagro estupendo!, al día siguiente, al sacarlo del agua, vieron todos con admiración que había aparecido claramente delineados los ojos, frente y nariz de una preciosa imagen. Ahí tienes, joh cristianos!, una saludable lección que te da la virgen en esa renovación maravillosa. (Arquidiócesis de Bogotá, 2006, p. 6)

Según propone Gaitán (2016) a partir de la reconstrucción documental de la aparición, la fecha se puede fijar en 1696. En esta ocasión, fue la india ${ }^{2}$ viuda de Diego Sacabuche quien heredó el lienzo a fray Antonio Montero, de la Orden de San Agustín, y fray Pedro Ramos, padre predicador. Luego sucede lo descrito en la Novena: la aparición del rostro de la virgen tras haber pasado por el agua, tarea encargada al indio Murillo, ayudante del cura Montero. En consecuencia, considerar la autoría clerical del milagro permite establecer una guía de lectura para comprender la resignificación que opera la Iglesia católica sobre un territorio por domeñar, para lo que estableció la devoción mariana como una práctica tendiente a la integración de las poblaciones indígenas y mestizas. La devoción entonces realzaba la escenificación prehispánica con la intervención de los indios Diego Sacabuche, su mujer y el ayudante Murillo, "naturales de la parte

2 Es de anotar que el uso de esta palabra en particular hace una aproximación historiográfica y en ningún momento es reflejo de una apreciación peyorativa. 
de Tapias, ubicado cerca al pueblo viejo de Ubaque, donde originariamente se ubicaba el cercado del cacique Don Francisco de 1563" (pp. 116-117).

Pero la participación de la comunidad prehispánica cobra mayor fuerza con la decisión de apellidar a la virgen Nuestra Señora de Belén de Bochica. Como advierte Gaitán (2016), si bien el testimonio documental permite reconstruir el relato fundacional del milagro de la aparición, resulta llamativo que entre los pobladores de Ubaque la virgen tuvo su primera aparición en el cerro que lleva su nombre (cerro de Bochica, ubicado actualmente en la vereda de Belén), estimación que coloca en tensión la versión dada por la orden religiosa. En consecuencia, como culto instaurado por la Orden de San Agustín encargada del adoctrinamiento de los indígenas del valle de Ubaque desde mediados del siglo XVI, se retoma y re-posiciona el apellido de una deidad muisca como una estrategia tendiente a generar el consenso, para reafirmar entre la población "un ícono que tras siglo y medio de impacto colonial se mantenía vivo en el imaginario colectivo" (pp. 144-147).

La aproximación general a la aparición mariana se retoma como hecho particular que permite describir y delinear los posibles intercambios entre lo indígena y lo católico, por lo que uno y otro se erigen en marcadores identitarios. En entrevista realizada a Fabio Pardo, autor de Quinientos años de historia chiguana (1996), un libro pensado para escribir la "historia real" del municipio de Choachí, para el primer número del periódico de circulación mensual Expresión de Oriente, puntualiza que, según la investigación de fuentes documentales, "[los chiguanos] tenemos una raíz grande como la chibcha, el elemento indígena lo tenemos - así sea muy lejos - y estamos mezclados con la tradición española, la religiosidad por lo menos es un elemento español" (Martínez, 1995). Ahora, al procurar dar un sentido originario al nombre del municipio de Choachí, Pardo (1996) transmite una percepción basada en una concepción mitológica, por cuanto el territorio está habitado por lugareños "del valle, a cuyo fondo corre el río Absa [actual río Negro], y en las noches aparece Chía siendo el territorio 'Nuestro Monte Luna' o ‘CHIGUACHI'” (p. 5).

Esta percepción de intercambios entre el "elemento indígena" y la "tradición española" se rastrea igualmente en el testimonio de uno de los asistentes a la versión décima de la caminata Bogotá-Ubaque. Durante la jornada del 24 de enero de 1998, los caminantes estuvieron "acompañados por el dios de otras épocas, 'el astro sol', quien estuvo siempre atento a que sus protegidos no siguieran asesinando parte de su existencia, el Páramo". Un dios lejano que recordaba a los 680 caminantes el compromiso del cuidado del ambiente, un acuerdo sellado con "los claveles blancos del altar donde reposa la Virgen [de Belén], y el grito victorioso 
de las campanas", símbolos encargados "de dar la recibida a los que se mueren por soñar con la vida" ("La caminata de la Virgen", 1998, p. 7).

La producción y la circulación del "elemento indígena" y la "tradición española" no han perdido fuerza. En el desarrollo del conversatorio "Justicia ambiental y buen vivir: el caso del agua en Choachí, Fómeque y Bogotá", desarrollado en las instalaciones de la Universidad de San Buenaventura ${ }^{3}$, llamó la atención de los participantes la intervención de uno de los asistentes quien realizó una reflexión sobre el conflicto entre la ciudad de Bogotá y los municipios vecinos por el suministro y cuidado del agua; un discurso mediado por palabras provenientes, a su haber, del lenguaje muisca, al considerarse él mismo un descendiente muisca. La reflexión se selló con una danza y unos cánticos, escenificación tendiente a "hacer un matrimonio con la madre tierra [...] a través del principio creador que denominamos Atchum"4:

Entonces ese canto, para que lo vayamos aprendiendo, dice: "Atchum mi, atchum mi, atchum mi...". La palabra "chi" quiere decir nuestra placenta de vida, el lugar donde todo nació; "atchum mi, atchum mi, atchum mi, atchum mi, Chi", y después llamamos a la madre: "Bagu bagüe, Bagu bagüe, caca bagüe, bagüe bagüe bagu, chi"; después al padre: "chipa chipa mi, chipa chipa mi...". "Chi" es lo nuestro también, padre y madre, y después llamamos al hijo, que es como para decir que es el mismo Jesucristo, solo que nosotros lo llamamos "Chiminigagua", ¿sí? (S. Caicedo, comunicación personal, 11 de agosto de 2017)

Los entrecruces descritos entre lo indígena y la religiosidad católica señalados hasta el momento fijan contornos de aproximación. En línea con algunas problematizaciones sobre la reconfiguración de la religión en el mundo contemporáneo, la intención del artículo está guiada por la interpretación de articulaciones e influencias de las creencias en las apropiaciones del territorio y las

3 El conversatorio fue promovido por el investigador Servio Caicedo dentro del proyecto de investigación señalado más arriba. Se desarrolló el 11 de agosto de 2017 y contó con la participación de académicos de la Universidad de San Buenaventura, quienes compartieron reflexiones junto con miembros de organizaciones sociales de los municipios mencionados: Fundación La Minga, Corporación La Talanquera, Casa del Maíz, Veeduría Ciudadana, padres de familia y alumnos de la Institución Educativa Ignacio Pescador.

4 Elmaterial de audio fue suministrado por el profesor Servio Caicedo, perola transcripción es propia. Valga por ahora la aclaración de que las palabras utilizadas no corresponden al uso de una lengua existente propiamente, el muyscubum, por cuanto se debate en la actualidad si ella es o no considerada una lengua muerta entre los grupos que se autodefinen como herederos de los muiscas (Gómez, 2009). 
construcciones de la territorialidad. Para ello, se propone el diálogo entre los discursos de dos grupos diferenciados en los municipios de Choachí y Ubaque: a) los buscadores espirituales, cuyo lugar de enunciación se establece por la reactualización de una tradición muisca, sin ser ellos pertenecientes a un cabildo indígena establecido por ley; y b) representantes del clero, quienes en su comunicación transmiten algunos elementos para comprender, de manera particular y sin ánimo de generalizar, la reconfiguración de lo católico-institucional en la actualidad.

La hipótesis por desarrollar es que el territorio es un registro, índice y factor de la disputa por la resignificación del pasado, en la distinción entre la memoria por lo ancestral (lo muisca) y el peso de una tradición (la religiosidad católica), en tanto que la territorialidad aboga por la confluencia armoniosa (aunque conflictiva) consecuente con la producción de sentidos propios de la circulación de las creencias en el mundo contemporáneo: mientras el territorio es firmeza, la territorialidad es la creencia en acto.

El trabajo estará divido en cuatro partes: en primer lugar, la diferenciación entre territorio y territorialidad; en segundo lugar, una aproximación particular para el estudio de la reconfiguración de la religión en el mundo contemporáneo; en tercer lugar, el abordaje analítico de los discursos de los buscadores espirituales y los representantes del clero; $y$, por último, algunas conclusiones preliminares.

\section{Apropiaciones del territorio y construcciones de territorialidad}

Esta sección parte de considerar la condicionalidad histórica que repercute tanto en las preguntas por hacer para las definiciones teóricas del territorio y la territorialidad como en las experiencias de los actores sociales que las influyen. En este sentido, se retoma la propuesta de Segato (2008), para quien la periodización de la historia de las formas de gobierno, esbozada por Michel Foucault, permite rastrear políticas espaciales. En este sentido, al modelo feudal del gobierno del territorio, en cuanto espacio de tierra bajo el poder de un señor o monarca, le sucede el modelo del gobierno de la población, en cuanto administración de la vida del grupo humano más que del territorio. Ahora, en tiempos de la globalización del Occidente tardío, se asiste a una nueva política espacial en la que es la población que ahora diseña y captura el territorio; una posibilidad consecuente con la pérdida gradual de la localización y del anclaje inequívocamente espacial de 
la población por ser gobernada. Por tanto, los diferentes grupos que componen el universo de la nación producen diferencias para fijar identidades, leídas estas últimas como lealtades comunes; es decir, formas particulares que garantizan la adhesión de los miembros por sus maneras propias de representación y dramatización ante el mundo.

En esta nueva política espacial, el territorio se lee entonces como una construcción particular del espacio geográfico. Una totalidad en la que se resuelve y se materializa la existencia humana, atravesada por tres ámbitos complementarios: a) las prácticas espaciales por las que se asegura la apropiación, la percepción y el uso del espacio; b) las representaciones del espacio; y c) los espacios de representación en tanto conjuntos de símbolos y lugares clandestinos de la vida social (Mançano, 2009; Osorio, 2009).

Estos ámbitos se encuentran cruzados por la historia y la memoria de los agentes que interactúan con el territorio, por lo que este puede abordarse como una significación: una producción cultural que recoge e inscribe las prácticas sociales que en él se desarrollan, asegurando la apropiación, percepción y habitación del espacio por los diferentes grupos sociales que en él interactúan (Nates, 2011). Pero significación, igualmente, por la incidencia directa en la gestación de identidades propiciadas por y desarrolladas en el territorio, que colocan en juego las vinculaciones simbólicas de pertenencia a un todo biosocial y determinan las formas de ser y los orígenes, así como los referentes culturales y sociales con respecto a los otros (Lozano, 2009).

En este camino de la producción cultural del territorio, se percibe en complemento la autofabricación de un sujeto territorial, "en el sentido de un sujeto de derecho, pero también de la historia de su propia historia", según puntualiza Hoffmann (2016, p. 19), quien, además, agrega una diferenciación relevante entre tierra, territorio y territorialidad que resulta sugerente para rastrear las historias particulares de los sujetos territoriales. Mientras la tierra se entiende como un recurso para explotar y cultivar (fuente de disputa en la larga historia del reconocimiento inacabado de lo campesino a lo largo del siglo XX hasta el presente), el territorio es índice y factor del espacio apropiado, una fuente de negociación y una condición de posibilidad para el acto de habitar por parte de diferentes grupos sociales, que se valen de mitos, relatos y antepasados en el camino de la territorialización, estrategias que realizan los sujetos territoriales para fijar los límites del espacio habitado (Nates, 2011).

Y en el entrecruce de estas diferenciaciones entre el recurso y la posibilidad de habitar un espacio, la territorialidad se asume en un conjunto movible que le da sentido: 
Si "la tierra" es un recurso medible, "el territorio" implica sujeto y subjetividades. No se define solamente por rasgos objetivables, sino también por prácticas de uso, percepción y representación, es decir, por juegos de territorialidades que mantienen los actores con sus espacios. (Di Meo y Raffestin, 2011, citados por Hoffmann, 2016, p. 20)

Dichos juegos de territorialidades no solo procuran asegurar los diferentes sentidos de posesión y pertenencia, sino que se perciben casi que como un sentimiento (Nates, 2011) que se construye en su doble representación, física e intelectual, y que vehicula las diferentes maneras de vivir el territorio por parte de los grupos sociales, situación que supone "relaciones y superposiciones conflictivas entre territorialidades que comparten y compiten por el mismo lugar" (Meza, 2008, p. 441).

En este punto, tanto la etnicidad como la religión se tornan en "repertorios disponibles de signos de filiación cultural" y "marcas de posesión" que aseguran la representación del territorio y el sentimiento de territorialidad en la nueva política espacial descrita más arriba. Para el caso de la religión, Segato (2008) propone:

Al abandonarse el paradigma de la fijación de un territorio con monumentos religiosos - edificaciones o consagraciones del paisaje-, lo que garantiza la territorialidad de una iglesia es la marca diacrítica y ostensiva impresa en los fieles y en los espacios baldíos y desiertos [las cursivas son mías] para la mirada mercadológica del presente, que la red de fieles ocupa y por los cuales transita. Estamos en la época en que el rebaño es el territorio [las cursivas son mías]. (p. 50)

Afirmación esta última que invita a pensar hasta qué punto es posible ampliar el argumento a religiones no institucionales, cuestionamiento válido para este artículo y para rutas futuras de investigación. Aun así, la invitación de Segato (2008) de pensar la religión en el mundo contemporáneo abre la veta para la próxima entrada, no sin antes matizar que las definiciones y diferenciaciones entre territorio y territorialidad tal y como se han expuesto hasta aquí dan cuenta de una aproximación de constante complementariedad entre el proceso de subjetivación, por un lado, y la apropiación del espacio y la puesta en juego del territorio, por otro. 


\section{La reconfiguración de lo religioso en el mundo contemporáneo: new age y circulación de creencias}

Para el estudio de la reconfiguración de la religión en el mundo contemporáneo, para y desde América Latina, se comparte la mirada crítica al cuestionamiento hacia los alcances limitados de la proyección de la tesis de la modernización, según la que el proceso irreversible de la secularización sería una de las garantías del desarrollo económico y político, tal y como se presuponía que había sucedido en los contextos anglosajón y europeo. Ante la diversidad de manifestaciones de lo religioso en la esfera pública, que "retornaban" con fuerza desde mediados del siglo XX, pronto se hizo necesario volver sobre los derroteros que fundamentaban la inevitabilidad del agotamiento de la religión en el Occidente tardío.

Como apunta Hervieu-Léger (2005), uno de los problemas inherentes a tal proyección modernizante es la definición de la religión, por cuanto los especialistas se encuentran presos de la herencia de la totalidad de la "hegemonía del cristianismo en el pensamiento religioso y, en particular, sobre el análisis de los universos modernos de significados" (p. 117), lo que obstaculiza el análisis tanto de los desplazamientos de las religiones históricas hacia las "zonas profanas convertidas en autónomas" como de su recomposición y otras manifestaciones religiosas, en un contexto delineado ahora por la abierta competencia por la diversidad de modelos de producción de trascendencias, valores morales, creencias y producciones de la distinción sagrado-profano. La pregunta por la reconfiguración de lo religioso abre entonces la posibilidad del estudio de sus continuas transformaciones y relocalizaciones. A una desinstitucionalización de las religiones históricas, en sus formas de control y de gestión de acceso a las experiencias sagradas y de las creencias trascendentes, le sucede una recomposición al estilo "hágalo usted mismo", un desplazamiento abierto por el permanente movimiento de la modernidad que ha afectado la estabilidad de los sistemas religiosos históricos.

En este orden de ideas, el problema de la definición debe ahondar en una mayor caracterización de las transformaciones de lo religioso, porque, como lo advierte Hervieu-Léger (2005):

En el universo "fluido", móvil, del creer moderno, liberado de la tutela de las instituciones totales del creer, todos los símbolos son, pues, intercambiables, combinables, y pueden trasponerse los unos a los otros. Todos los sincretismos son posibles, todos los nuevos empleos son imaginables. (p. 127) 
¿Por qué recurrir a creer para resolver el problema de la definición? Hizo mella en la academia francesa la propuesta de Certeau (2010) en torno a la antropología del creer. A partir de la pregunta por la reconfiguración del cristianismo en la modernidad (una época que impacta directamente las referencias "totalizadoras" que vienen de la tradición, tomadas ahora como "particularidades" que aparecen en un "paisaje desordenado" en busca de otros principios de coherencia), la pregunta para el investigador no parte ya exclusivamente del objeto del creer (un programa o un dogma), sino más bien de la voluntad del hombre religioso por participar de una proposición que se tiene por cierta, una convicción atravesada por el acto de hacer creer que se cree (como aclaran Ospina y Sanabria, 2004). Creer, en suma, es la producción de una legitimidad, una demostración de aquello que se hace con lo que se dice que se cree.

Recontextualizando este abordaje teórico para el contexto de América Latina, De la Torre (2013a) analiza la transformación contemporánea de lo religioso en el continente a partir de la sugerencia de no obviar la convivencia entre las proyecciones de la producción de lo sagrado en la globalización, por un lado, y la pervivencia de una religiosidad popular, por otro, por cuanto ambos dan cuenta de un sincretismo adaptativo y performativo propio del contacto entre la Iglesia católica y las religiones tradicionales de las comunidades indígenas y africanas. Este intercambio (con su genealogía en la conquista colonial) se traduce en el ámbito de la religiosidad, no en una "yuxtaposición entre diversas culturas, sino sobre todo [en] una matriz generativa de síntesis entre creencias diversas", que se desenvuelve en su capacidad de responder a las tensiones entre la "asimilación y el rechazo a la modernidad, entre la resistencia cultural de las tradiciones y su respuesta para generar vías de ser y estar en la modernización contemporánea" (párr. 21-23).

En este sentido, la religiosidad popular, antes que ser un sistema religioso propio, es una cualidad característica para América Latina, determinante en la recomposición y producción históricas de lo religioso a partir del sincretismo que la determina. Las cosmovisiones indígenas familiarizadas con el curanderismo, la magia, el animismo o la santería conviven con el catolicismo articulador de la devoción a vírgenes, los santos y el milagro, y se encuentran en contacto con la religiosidad propia de la era de la globalización cultural, cuyo sello característico es la continua generación de novedosos hibridismos (De la Torre, 2013a), entre ellos, las prácticas agrupadas, la clasificación, por demás limitada, del new age.

Como sensibilidad posmoderna y contracultural que emergía en la década de 1960 entre los sectores de la clase media ilustrada de los centros metropolitanos de los Estados Unidos (con epicentro en California) y Europa, los new agers 
cosmopolitas se agrupaban en torno a la búsqueda de experiencias místicas en lo que suponían eran los "límites que habían sido negados o rezagados por la propia modernidad occidental: lo oriental, lo indígena y la naturaleza". Articulaban entonces ofertas de sanación y espiritualidad alternativas frente al materialismo del progreso capitalista y al racionalismo de la modernidad, importando técnicas y sabidurías sustraídas de antiguas religiones de Oriente, además de temas cósmicos (como la astrología y el contacto con los extraterrestres). En su búsqueda de lo alternativo, fundamento del individualismo y el self, la universalidad y el relativismo cultural, los buscadores espirituales pronto volvieron sus ojos sobre las prácticas indígenas y africanas en América Latina, por lo que revalorizaron tradiciones negadas y desvalorizadas por la historia de Occidente con el ánimo de rescatar la "pureza de los productos nativos, lejanos y ancestrales", a los que calificaban de "representantes de autenticidad y ancestralidad [las cursivas son mías]" (De la Torre, 2013b, pp. 27-31).

Revalorización que se ejemplifica en el contexto colombiano con la práctica, cada más vez extendida, de la verdadera toma del yajé por parte de personas y agrupaciones de estratos socioeconómicos medio y alto, con acceso a educación universitaria en la ciudad de Bogotá, y tema de estudio de Sarrazin (2008a, $2008 b, 2012)^{5}$, quien identifica en ello una serie de reinterpretaciones "espiritualizantes" de lo indígena, consecuente con el deseo de dar sentido a la búsqueda personal de una espiritualidad alternativa por parte de los practicantes. Con este fin, los buscadores espirituales comparten una visión del indígena como un ser esencializado y ahistórico que no destruye, no es ambicioso, no es violento y que tiene la capacidad de hablar con la naturaleza, como en el chamán-médico, una figura mediadora que logra sanar el cuerpo humano a partir del restablecimiento de la armonía global.

Restablecimiento consecuente con la búsqueda de una espiritualidad que se asume como terapéutica o de ayuda para sentirse mejor; una respuesta al contexto global de ausencias de vida espiritual y sentido trascendente en la vida. Una búsqueda, por demás, sustentada en la creencia en que los orígenes de las dolencias son psicológicos, espirituales o ecológicos (al encontrarse todo conectado en la vida), tal y como lo rastreó Sarrazin en las palabras de una especialista en psicología comunitaria, asistente a rituales chamánicos, quien se desempeñaba como rehabilitadora de jóvenes drogadictos (por tan solo extender un ejemplo de tantos):

5 Puntualiza Sarrazin (2012): “El yajé, escrito a veces yagé, conocido en otros países como ayahuasca, y cuyo nombre científico es Banisteriopsis caapi, constituye el ingrediente principal de una bebida alucinógena consumida en rituales de pueblos indígenas de la Amazonia" (p. 142). 
Ahora la gente busca el sentido por unas rutas diferentes, por ejemplo, mirando hacia adentro. Oriente [refiriéndose a las culturas de países como India o China] dice que la gente busca por fuera lo que tiene que buscar en su interior. [...] Vamos a ese mundo primitivo, a lo indígena, a lo campesino, a las comunidades negras... Es toda la búsqueda del sentido que no se encuentra en el mundo de la ciencia, de lo racional. Y hay una búsqueda de las dimensiones emocional, afectiva, espiritual. El mundo indígena está mucho más cerca del sentido, porque tiene [esa] visión holística del mundo. A mí el mundo indígena me parece mucho más cercano a lo espiritual. (2008b, párr. 17)

Se percibe entonces no solo la producción de una espiritualidad como producto alternativo, sino que también se abre paso a la dificultad por delimitar con precisión las expresiones de lo religioso en el mundo contemporáneo. En cuanto a esto último, valgan dos aclaraciones. En primer lugar, el uso de new age es utilizado como una categoría de análisis que recoge prácticas, imágenes y discursos agrupados de esta manera; una categoría para establecer la comunicación entre los investigadores y clarificar el tipo de objetos, prácticas y representaciones. Por otro lado, lo que caracteriza al buscador espiritual es su supuesta libertad individual para escoger como le plazca sus creencias y prácticas, la ausencia de una obediencia irrestricta a una autoridad centralizadora externa y la búsqueda del bienestar personal. En suma, como señalaría Carozzi (2006), una diversidad de modos de articulación entre religiones que no se encuentran controladas por asociaciones de especialistas en lo religioso.

Ahora bien, es relevante el llamado de De la Torre (2013b), para quien el encuentro de estas espiritualidades alternativas con las cosmovisiones indígenas, los saberes populares, las experiencias animistas y la magia chamánica generó intercambios culturales, y no exclusivamente una serie continua de difusiones en el contexto de la homogeneización globalizante. En este sentido, no es suficiente mirar la circulación de ritualidades, conceptos y saberes, si no se consideran la resignificación y la reapropiación popular del new age por parte de las religiones tradiciones afroamericanas e indígenas, que dotan y posibilitan otros sentidos en torno a lo sagrado-contemporáneo, sin perder sus formas patrimonializadas y sus funciones de producción de diferenciaciones en el seno del Estado nación.

Ahora bien, es relevante advertir que cualquier amalgama de expresiones culturales (ritualidades, conceptos y saberes provenientes de diversas geografías que atraviesan desde Oriente y se entrecruzan con lo nativo latinoamericano, en sus manifestaciones indígenas y afroamericanas) no puede reducirse inequívocamente 
a expresiones del tipo new age. Más que un discurso unificado, puntualiza De la Torre (2013b), el new age debe asumirse como una matriz de sentido, un marco interpretativo articulado en torno al principio holístico, que establece que todo se encuentra interrelacionado: el todo está contenido en las partes, pero a su vez las partes conforman el todo. Por tanto, el buscador espiritual produce una gramática capaz de "apropiar, traducir y refuncioanalizar diferentes aspectos culturales y espirituales de los otros, para hacerlos suyos" (p. 33), y así posibilitar una "unidad generativa holística global", en que la sacralización del self se traduce en la sacralización del cosmos.

Por lo dicho hasta el momento, se descubre la complejidad de delimitar la reconfiguración y el estudio de las maneras particulares de experimentar y significar, de encuadrar lo religioso en el mundo contemporáneo. Como advierte Ceriani (2013), la dificultad es resultado del consenso en el uso acrítico del concepto de religión para dar cuenta de la diversidad religiosa actual. Por ello, Ceriani extiende la pregunta y la invitación por la relevancia de la categoría de espiritualidad para dar cuenta de los distintos regímenes de legitimidad social, creencia e identidad (personal y colectiva) que atraviesan las adhesiones religiosas. En este sentido, y según un acumulado de investigaciones etnográficas de más de veinte años, la espiritualidad en el mundo contemporáneo se entiende como una apropiación consciente "post o trans religiosa, que busca significarse como una actitud simultáneamente universal a la especie humana e íntima y esencial de cada persona o cultura, donde la amabilidad, el pensamiento positivo y fraterno son claves" (párr. 11).

En síntesis, la argumentación propuesta en esta sección está orientada por la advertencia de Ceriani (2013) en cuanto a la dificultad para dar cuenta con precisión de la reconfiguración de lo religioso en el mundo contemporáneo. Para ello, se privilegió la descripción de algunas de las particularidades para y desde América Latina, con la característica de la producción sincrética de las religiones tradicionales, que conviven tanto con las producciones de sentido globalizantes en la matriz de sentido new age como con la perdurabilidad de la institucionalidad católica. Pero a la implosión de ritualidades, conceptos y saberes provenientes de diversas geografías, se suma el problema mismo de la definición, aspecto con el que se quería dejar enunciada la propuesta de la antropología del creer que rescata más el sentido del hacer creer que los contenidos de la creencia misma, una invitación que hace a partir de las prácticas de los agentes religiosos con el ánimo de delimitar las convicciones. 


\section{Invocaciones de lo ancestral y pervivencias de lo tradicional: creencias, religión, territorio y territorialidad}

Volviendo nuevamente al encuentro "Justicia ambiental y buen vivir: el caso del agua en Choachí, Fómeque y Bogotá", J. Laguna, cuyas palabras se encontraban fundamentadas por la reapropiación de la tradición muisca según aclaró desde un inicio, Caicedo recordaba:

La sabana cundiboyacense se está inundando no de comida, sino de químicos para fabricar comida, ¿eso estaría bien?, ¿qué se requiere para vivir bien? Tener lo necesario para estar, tener lo necesario y ser feliz, lograr ser feliz, y ser feliz, hablando acá dentro del tema de la Iglesia católica, yo una vez leí a san Agustín y él decía "es feliz el que logra encontrar a Dios, sé uno con Dios". ¿Y quién es Dios? Dice la Biblia, "Dios es todo"; dice el Bhagavad Gita [texto hindú], "Dios es todo". Y la Biblia dice: "Dios es padre y es madre, alfa y omega"; por eso, nos crearon a imagen y semejanza de Dios padre y madre, eso dice la Biblia. ¿Cuál es Dios Padre? Dios Padre es todo lo que vemos. ¿Ycuál es Dios Madre? Vea, esta [señalando el suelo], la que nos dio de comer, la que nos dio para vestirnos, la que nos dio para construir estas casas, la que nos dio esta mañanita, la que nos baña. "Cuando logremos ser uno con Dios, vamos a lograr ser felices", dice san Agustín. (S. Caicedo, comunicación personal, 11 de agosto de 2017)

El principio holístico se puede ubicar en la intención por localizar la divinidad en el entorno; la hibridación entre Oriente y Occidente se establece en el diálogo entre san Agustín, la Biblia y el Bhagavad Gita; la búsqueda del bienestar se traduce en la felicidad en Dios. Sin embargo, la intención de esta sección no es la descripción exclusiva de las prácticas y de los repertorios new age de un grupo de personas en los municipios de Choachí y de Ubaque. Animado por la intención de encuadrar una aproximación particular e inicial para el estudio de la reconfiguración de lo religioso en el mundo contemporáneo, se parte de la indagación por la influencia de las creencias religiosas en la construcción del territorio y la territorialidad, a partir de la hipótesis enunciada en la introducción.

A continuación, se enuncian algunas claridades necesarias. En primer lugar, el eje articulador del análisis está orientado por el supuesto de que, para dar sentido a la descripción de los contenidos de las creencias, se hace más sugerente no partir exclusivamente de las afirmaciones de validez de los creyentes, sino antes 
bien de las maneras en que se practican las creencias, con el ánimo de acercarse a las motivaciones, a los contenidos y a los funcionamientos de la voluntad del hacer creer. En segundo lugar, cuando se hace referencia a "lo muisca" en los municipios señalados más arriba, se está dando cuenta de la reapropiación y redefinición de una cosmogonía que se presenta como tradicional, ancestral y milenaria por parte de un grupo de personas que, en sus diferentes trayectorias de vida, resultaron reunidas en comunión en torno a la autodenominada Comunidad Mhuysca de Oriente, ${ }^{6}$ pero en ningún caso son miembros indígenas de los resguardos reconocidos actualmente por la legislación colombiana en el departamento de Cundinamarca (localidades de Bosa y Suba, y municipio de Chía) o en proceso de reconocimiento (municipios de Cota y de Sesquilé). Es de señalar en este sentido que lo que menos importa a este grupo es tal reconocimiento jurídico, que garantiza, entre otros derechos, la atribución y propiedad de un territorio delimitado para la comunidad 7 .

En este sentido, es sugerente dejar enunciada la pregunta de hasta qué punto la reivindicación de lo muisca, como algo ancestral y milenario, tiene un peso significativo por el contacto y diálogo con comunidades indígenas reconocidas jurídicamente. Cuestionamiento de peso, porque, como lo advierte Gamboa (2015) para el caso de la historia de los muiscas entre los siglos XVI y XVII, y según la reconstrucción y los testimonios documentales:

Los muiscas son una creación de los españoles y de la dominación colonial [...] Antes de la llegada de los europeos no había ningún grupo llamado muisca, ni había una unidad política o cultural, ni tampoco la zona estaba dividida en dos reinos. Lo que realmente existía era una serie de cacicazgos autónomos, por lo menos unos diez dentro de los cuales los de Tunja y Bogotá probablemente eran los más poderosos. (pp. 21-22)

Como tercera claridad, las personas con quienes se estableció comunicación comparten elementos de las caracterizaciones descritas más arriba para el new age, decidiendo aplicar el calificativo de buscadores espirituales por considerar que se guarda el respeto debido en el quehacer académico, en lugar de "neorrurales",

6 A lo largo de la investigación fue difícil establecer una historia fundacional de esta comunidad debido a la reserva de las personas con quienes se estableció comunicación. Hacia mediados de diciembre de 2018 se constituyó en Cabildo Mayor Muisca Oriente, que integra habitantes de los municipios de Ubaque, de Fómeque y de Choachí.

7 Esta apreciación es retomada en la historia de la situación del Cabildo Indígena Muisca de Bosa, cuyo reconocimiento se oficializó el 17 de diciembre de 1999, según describe Henao (2016). Agradezco la sugerencia de esta información a la antropóloga Ivonne Espitia. 
"neoindios" o "neomuiscas". Por otro lado, no es el objetivo la descripción uno a uno de los ritos, las ceremonias y los mitos que comparten o socializan dichos buscadores. La intención es rastrear algunos elementos por medio de los que proponen vincular sus creencias al territorio y a la territorialidad. Por último, valga decir que las apreciaciones de este grupo se colocan en diálogo con algunas valoraciones de miembros de la Iglesia católica, de modo que es la laguna de Ubaque el lugar obligado de intercambios de sentidos entre ambas agrupaciones.

¿Por qué la laguna? Más allá de la notoriedad de aquella en el paisaje del municipio de Ubaque, alrededor de la que se ha venido gestando un proceso de urbanización que ha afectado directamente el cuerpo de agua, es la evocación doblemente simbólica de un lugar de paso y de ritualidad. Como advierte C. Páramo, la laguna rememora históricamente un punto más dentro de la conmemoración del ritual prehispánico de correr la tierra, "que era una gran competencia, una gran romería que se hacía por unas personas seleccionadas por la comunidad [muisca], que se iban a recorrer todas las lagunas, siete o nueve lagunas que había" (comunicación personal, 20 de marzo de 2018). El ritual se hacía en tiempos del último solsticio del año (del 22 de septiembre al 21 de diciembre para el calendario gregoriano) por parte de los grupos muiscas que habitaban el actual altiplano cundiboyacense, y así cubría los territorios de Ibagué, la sabana de Bogotá y el departamento de Boyacá, y estaba animado por ofrendas a los ancestros y a los dioses en agradecimiento por el año que fenecía y por los deseos para las buenas cosechas del maíz venideras.

Pero la laguna no perdura exclusivamente como espacio de rememoración. Punto importante es que la laguna habla, según refiere C. Páramo:

[Ella] es importante porque ahí está el mito de origen, ahí fue donde Cochavira y Bagüe, todo ese nacimiento de la nación muisca fue ahí, ahí es donde se plasma [...] entonces uno hace la caminata, y pasa una noche entera en Bagüe, con fuego o sin fuego, solamente ahí, concentrado con la laguna, la laguna te habla. Nosotros vivíamos como a tres minutos, ahí donde te digo, y siempre, a las tres de la mañana, se sentía cómo entraba la niebla en la casa, entonces era como si Bagüe se levantara y fuera a recorrer toda la montaña del Guayacundo y el Qüinto. (comunicación personal, 2 de septiembre de 2018)

No es tan solo mito. La experiencia de la comunicación con Bagüe va más allá de la mera evocación de una deidad indígena anclada en el pasado. La manifestación de una presencia atemporal en el ahora algo indica, por ello, la necesidad de hablar del mito de origen, toda vez que la reactualización parte de 
rescatar el origen de la vida del mundo como resultado de la fecundación de la diosa mujer que sale de la laguna (Bagüe) y procrea a su hijo (Iguaque), que juntos pueblan el territorio (muisca); ambas deidades son entonces portadoras y dadoras de vida. Pero ¿con qué objetivo hablar desde una reactualización de una tradición a la que no se pertenece, de la que los rasgos de una herencia son poco fiables? Al avanzar la conversación, C. Páramo puntualiza que los "rituales de pagamento sirven para mantener el equilibrio del sistema natural". Y no habla desde el pasado. La invitación que hace es "entender la vida de manera diferente" (comunicación personal, 20 de marzo de 2018), donde la naturaleza tiene algo que decir. En este sentido, el agua (como medio de vida en la invocación a la figura de Bagüe) remite a una manera particular de experimentar la armonía entre el hombre y el medio que lo rodea. Territorios de agua, como lo son los municipios de Choachí y de Ubaque, pasan por desapercibidos para la ciudad de Bogotá (que también fue agua), resguardada por los cerros orientales de toda exterioridad, segura en el aprovisionamiento del mineral vital para sus habitantes, pero al fin y al cabo ciudad, cuyos afanes de expansión y urbanización se cimentan sobre el desconocimiento de las formas de vida tras Monserrate y Guadalupe (J. Díaz, comunicación personal, 25 de enero de 2018).

En el diálogo sostenido por J. Laguna (comunicación personal, 13 de febrero de 2018) con algunos estudiantes universitarios, reunidos en el desarrollo del encuentro "Justicia ambiental y buen vivir", advierte sobre el desconocimiento de que Chingaza sea el proveedor del agua que se toma en la ciudad de Bogotá, un páramo más próximo al municipio de Choachí que al municipio de Ubaque. Esta vez no se habla de la laguna, pero se advierte del "trabajo espiritual" realizado ocho días antes para pedir "permiso en el territorio" a la "laguna sagrada del páramo" con el fin de garantizar la compañía de la "madre espiritual". No resultaba gratuito el trabajo, pues, al pedir permiso al territorio para asegurar la compañía de la madre, C. Páramo se autofacultaba para convertirse en guía y mediador, quien, portando una bendición del territorio sagrado, aseguraba el vínculo momentáneo para firmar nuevamente la ley de origen entre él y la comunidad de estudiantes, en procura de erigir el medio ambiente como un objeto de devoción, aunque fuera por un instante.

J. Laguna (comunicación personal, 13 de febrero de 2018) extendía, entonces, a sus espontáneos seguidores "unos cánticos que tenemos como para meditar y para también traer esa energía de allá [del páramo y la laguna]”. Con esta intención, comparte a sus interlocutores las siguientes palabras, no sin antes advertir que el canto debía estar acompañado de la danza, porque "así hacemos los muiscas": 
Se comienza con un canto a la laguna y a la madre tierra que en español dice: "Yo soy la tierra, la tierra soy yo. Yo soy el agua, el agua soy yo. Yo soy el aire, el aire soy yo. Yo soy maíz, maíz soy yo. (S. Caicedo, comunicación personal, 11 de agosto de 2017)

El todo en las partes y las partes componiendo el todo; los elementos del entorno posibilitando al ser en armonía con la naturaleza. El principio holístico se puede rastrear, entonces, en los discursos de J. Laguna y C. Páramo. Sus invitaciones dan cuenta de su articulación y participación en circuitos new age, y la extensión de sus prácticas e ideas, que procuran lograr el convencimiento de experiencias encarnadas, parecen estar guiadas por la demanda de sentido de los buscadores espirituales. Pero pronto sobresale una pregunta que pareciera sencilla de responder: ¿qué es lo que ellos quieren decir? Laberinto tal vez sin salida, porque procurar dar cuenta del sentido de cada uno de los contenidos de las agrupaciones de las creencias de estos buscadores implicaría no solo un trabajo más exhaustivo, sino además partir de un supuesto teórico y metodológico: el deseo de estabilidad de un sistema de creencias a partir de ellas mismas. En este sentido, no está de más agregar que tal estabilidad es tan solo una expectativa en el grupo que se ve obligado a convivir con la inestabilidad del contacto cotidiano del exterior. En esta tensión es donde se inserta la pregunta por el territorio y la territorialidad en la medida en que, como advierte De la Torre (2013b), una de las particularidades de la new age en América Latina es que "se enraíza y contribuye a recrear el territorio" (p. 35), manifestación particular de la producción de nuevas identidades étnicas en la fascinación por lo nativo, lo indio y lo ancestral.

Cabe la advertencia de que la tensión entre la estabilidad e inestabilidad de las creencias y la generación de nuevas identidades étnicas atravesadas por la fascinación no es exclusiva de los buscadores espirituales de los municipios de Choachí y de Ubaque. Por el contrario, es una tendencia que ha venido cobrando fuerza como consecuencia de las diversas posibilidades de lo religioso en el mundo contemporáneo. Es relevante en este punto el caso estudiado por Gómez (2009) en torno a la autodenominada Nación Muisca Chibcha, grupo de personas que comenzó a organizarse en la maloca huitoto del Jardín Botánico de Bogotá, dirigidos por el abuelo Sigifredo o Suaga Gua, Hijo del Sol al servicio de la Madre, como se autoproclamaba. Sus miembros se identificaban como muiscas luego de asimilar supuestas prácticas indígenas (rituales de pagamentos, limpias de tabaco, rituales de fuego, danzas, convites y círculos de palabra) y participar de rituales de paso.

Lo más relevante no era la puesta en escena de las rutinas indígenas para forjar la identidad de esta nación, sino más bien la construcción de una memoria 
pretendidamente común, donde el linaje espiritual y el origen son movilizados como estrategias discursivas para superar los lazos genéticos de parentesco. Lo que se termina compartiendo con mayor firmeza es un pasado pretendidamente común. El territorio, dentro de este juego de narrativas que es la memoria, cumple entonces la función de veracidad de localización de las prácticas definidas como ancestrales. Memoria y territorio permiten imaginar y soportar una identidad colectiva.

No es gratuito, por tanto, que C. Páramo (comuicación personal, 20 de marzo de 2018) haga énfasis en la pregunta de cómo despertar el territorio. Motivado por fundamentar un origen muisca, recurre a la invocación del territorio con un calificativo ancestral en la afirmación "este territorio tiene su raíz en el territorio muisca" (J. Díaz, comunicación personal, 25 de enero de 2018), según dijeron en círculos de palabra los abuelos indígenas de la Sierra Nevada de Santa Marta, del departamento del Amazonas y de la Sierra Nevada del Cocuy. Esta comunicación con comunidades indígenas no es gratuita. En el camino de producir una memoria, los buscadores espirituales hablan de contactos, apropiaciones y usos de instrumentos y saberes indígenas, tales como el tabaco de coca, el ambil, el rapé, la pipeta, el tejido, el murundí o el polvo de tabaco, el poporo, el tututosma o gorro, el yagé, el mambé y el mezcal (Gómez, 2009), lo que en palabras de C. Páramo (comunicación personal, 20 de marzo de 2018) se denominan las "plantas de poder". En este punto, son interesantes los elementos que se pueden rastrear en la historia fundacional del Cabildo Indígena Muisca de Bosa. Según uno de sus integrantes, los contactos con indígenas del municipio de Sesquilé, el departamento del Putumayo y de la Sierra Nevada de Santa Marta, así como sabedores del pueblo inga y del departamento del Amazonas, fueron de suma importancia para retomar el conocimiento de las plantas, de la vida en comunidad, de los pagamentos al territorio y de la memoria de los abuelos (Henao, 2016, p. 27).

Por otro lado, despertar el territorio es desarrollar la capacidad de descifrar la energía guardada en el territorio; es intuir una memoria que no es hablada. Dejando de lado la sensación de indescifrabilidad de la comunicación, lo que resulta para C. Páramo (comunicación personal, 20 de marzo de 2018) relevante es "tratar de entender que la montaña, que el árbol, que la laguna tienen algo que decirnos a nosotros", porque ellos resguardan un legado que los muiscas dejaron plasmado en el territorio (J. Díaz, comunicación personal, 25 de enero de 2018). ¿Cuál legado? Tal vez "mantener el equilibrio del sistema natural" C. Páramo 
(comunicación personal, 20 de marzo de 2018), porque a lo largo de la investigación resultó inaccesible rastrear los contenidos de un legado ${ }^{8}$.

En este punto, es relevante proponer que, más que un obstáculo, la importancia de la construcción de una memoria cobra mayor importancia que la necesidad de dilucidar un misterio, que toma aquí la forma de un legado. Así, no es exagerado afirmar que el territorio para J. Laguna (comunicación personal, 13 de febrero de 2018) y C. Páramo (comunicación personal, 20 de marzo de 2018) es una construcción social que posibilita el despliegue de la memoria a partir del reconocimiento de lo ancestral, cuyos contenidos que refieren a un pasado se resuelven en el presente, plasmados como la garantía de un bienestar para el futuro a través de una narrativa que se refiere a lo propio como a lo único. Esto último haciendo referencia a una puesta en práctica de una visión esencialista del territorio en que algunos puntos específicos del paisaje (como la laguna de Ubaque o el páramo de Chingaza) se tornan en "lugares únicos que no pueden ser replicados o sustituidos: lugares celosamente cuidados por espíritus de la naturaleza que amenazan a quienes los atraviesan sin ser autorizados para esto" (Segato, 2008, p. 50).

Un punto importante es que la atribución del equilibrio del sistema natural reconocido por los buscadores espirituales también se hace presente en un sector de la Iglesia católica. Esta resulta ser la apreciación del padre J. Cano (comunicación personal, 21 de octubre de 2018), responsable del Santuario de Belén de Ubaque, a quien después de preguntársele por su impresión por la laguna manifiesta su desconocimiento de la leyenda por haber llegado recientemente a la parroquia (hacia mediados de 2018), aunque muestra su deseo de "conocer toda la historia de lo que implica el espíritu muisca, que es meterse en aquellos que vivieron de verdad, que estimaron, que miraron esa naturaleza". En este sentido, para el padre J. Cano, la tarea es retomar un mensaje para tomar conciencia "de lo que [hoy] dejamos de hacer", porque los ancestros muiscas hicieron "un esfuerzo grandísimo, precioso, que nosotros no le hemos dado la dimensión que realmente se requiere".

La invitación del padre J. Cano no solo demuestra la intención de diálogo con lo diferente de lo católico, sino que además está permeado por las posturas que se han manifestado en las producciones vaticanas desde mediados del siglo

8 Sarrazin (2008b) puntualiza que, para los sectores sociales bogotanos en búsqueda de la espiritualidad indígena como garantía de bienestar, sobresale la creencia del cuidado del medio ambiente como un emblema exclusivamente étnico. En este orden de ideas, refiere una de las personas entrevistadas: "ellos [los nativos] saben que todo en el universo está conectado y que hay que saber conservar lo que Dios nos dio" (párr. 15). 
XX, con el papa Pablo VI hasta el papa Francisco, que giran en torno a la propuesta de un desarrollo sustentable, del desarrollo humano y de la ecología integral, en crítica a la economía deshumanizada, el cambio climático y la degradación social, como advierten Cruz y Mallimaci (2017). Postura que se retoma con la divulgación de la encíclica Laudato si' en 2015 por el papa Francisco, que enmarca la crisis ecológica en la crisis ética, espiritual y cultural derivada del desarrollo industrial propio de la modernidad capitalista, conjugada con la creencia de que el mercado tiene la capacidad de resolver los problemas sociales y ambientales. En sus palabras:

En algunos círculos se sostiene que la economía actual y la tecnología resolverán todos los problemas ambientales, del mismo modo que se afirma que los problemas del hambre y la miseria en el mundo simplemente se resolverán con el crecimiento del mercado. Quienes no lo afirman con palabras, lo sostienen con los hechos, cuando no parece preocuparles una justa distribución de la riqueza, un cuidado responsable del ambiente. (Francisco, 2017, citado por Cruz y Mallimaci, 2017, p. 79)

Para el padre J. Cano (comunicación personal, 21 de octubre de 2018), la encíclica Laudato si' de Francisco se traduce en la práctica eclesial particular de la pastoral ecológica, encaminada a establecer una relación digna y armónica con la naturaleza, y orientada por el cuidado de nuestra casa común. En este orden de ideas, “¿para qué nos sirve la naturaleza? Ahí, a tenerla de adorno, ¡no!; al contrario, es vivirla, es convivir con ella, es saberla estimar, mimar, consentir". Ahora, punto a destacar es que las maneras en que se formaliza la pastoral en la parroquia abarcan, desde la promoción de grupos de cuidadores del páramo y nacederos de ríos, hasta la convivencia abierta con los buscadores espirituales, con quienes ha sostenido comunicación, manifestando una decisión que describe con las siguientes palabras:

No es cuestión de católico o no católico. Es más que todo iniciar ese diálogo porque ellos pueden ser creyentes o no creyentes, eso es lo de menos. Lo interesante es que hay una armonía en todas las religiones, para todos, creyentes y no creyentes. Lo que se llama la casa común, todos respiramos el aire, y si no le tenemos cuidado al aire para purificarlo, seamos creyentes o no creyentes, todos vamos a caer asfixiados.

Sin sopesarlo de manera directa, el padre J. Cano reconoce la pérdida del monopolio totalizador en la producción de sentidos de vida, al calificar de no creyentes a un conjunto heterogéneo de personas que supone han decidido salir 
del control exclusivo de la religión católica. Tal vez ello se deba a que el "aspecto espiritual está bastante confundido", en un contexto en el que "los valores están refundidos". En este sentido, la armonía de todas las religiones le permite al padre J. Cano (comunicación personal, 21 de octubre de 2018) hablar de la necesidad de una renovación de lo que "significa nuestros ancestros", en alusión a los encuentros que se están dando con algunas etnias, sin especificar cuáles ni en qué momentos.

Encuentros que también sostuvo el padre José Ovidio en 2018, antecesor del padre José Soto en el Santuario de Nuestra Señora de Belén desde 2013, quien logró la declaración de santuario en 2014. Una vez preguntado por la laguna, su respuesta fue contundente: "esta laguna está muerta espiritualmente, toda esa fuerza espiritual que tenía fue demasiado contaminada" (comunicación personal, 1 de septiembre de 2018). De esta manera, extendía y compartía las impresiones de unos indígenas del departamento de La Guajira con quienes en algún momento había hablado. Es difícil ahora ver en la laguna un "espejo en el cual podemos vernos con la deidad, en este caso el sol, que es una fuente de vida única e incondicional para nosotros". Dificultad que recoge dos hechos disientes: por una lado, la celebración de rituales ajenos a la fe católica, "más bien como de línea satánica, por algunos grupos de personas; prácticas que dañan el verdadero sentido de lo indígena, porque hemos confundido la espiritualidad indígena con chamanismo" (comunicación personal, 1 de septiembre de 2018); en segundo lugar, porque el proceso de modernización para el municipio ha posibilitado no solo la urbanización alrededor de la laguna, sino que además ha expuesto a los habitantes a los posibles peligros por la construcción de la carretera de cuarta generación, conocida como la Perimetral de Oriente, en el departamento de Cundinamarca. ${ }^{9}$

Dos consecuencias interesantes advierte el padre J. Ovidio (comunicación personal, 1 de septiembre de 2018) sobre esto último. En primer lugar, si bien puede traer beneficios económicos para el municipio, se interrumpirá la tranquilidad de los pobladores por la cantidad de gente extraña, "quienes llegan con costumbres, pensamientos e ideologías desconocidos". En segundo lugar, porque la carretera abrirá las condiciones para el desarrollo del turismo y el comercio

9 Según Rincón (2016), la vía conectará los municipios de Cáqueza, de Ubaque y de Choachí con los municipios de La Calera, de Sopó, de Guasca, de Guatavita y de Sesquilé, la mayoría de ellos ubicados al oriente del Distrito Capital, separados principalmente del perímetro urbano por el Área de Reserva Forestal Bosque Oriental de Bogotá. El trazado inicial ha generado una serie de conflictos, porque no se han considerado las apreciaciones de las comunidades; una de ellas es que en los sectores entre los municipios de Cáqueza y de Choachí es evidente la inestabilidad del suelo, según se pudo constatar en la salida de campo. 
religiosos, por lo que desvirtuará el conocimiento sobre la esencia del santuario, ya que, si bien este sería "más renombrado, más conocido", no se escaparía al "gran dolor de creer que hay que llenarlo de gente, porque así entonces se ve más el santuario".

De lo anterior se puede deducir una percepción negativa ante la posibilidad de transformación generada por el contacto con el extraño. Para el padre J. Ovidio (comunicación personal, 1 de septiembre de 2018), la feligresía del municipio de Ubaque se distingue porque tiene contacto directo con la divinidad a través de la naturaleza. En este sentido, "son personas muy sensibles a lo espiritual, tienen su origen indígena, y tienen también la posibilidad de estar cerca de manifestaciones naturales que referencian a Dios en la naturaleza". En este sentido, se recoge el peso de una tradición particular, animada por la intervención de Nuestra Señora de Belén de Bochica en la historia misma del pueblo, que dio una gran prueba de ello durante el terremoto de 1744 evitando la destrucción de las edificaciones del pueblo en respuesta a las oraciones de los pobladores, y que en la actualidad sigue haciendo presencia con actos de curación de enfermedades a sus fieles. Por tanto, no es exagerado proponer que la lectura de la fuerza y pervivencia de la devoción católica, así como su amenaza por el contacto con el extraño, se encuentra atravesada por un discurso eclesiástico que se caracteriza por que opera una transformación del territorio cotidiano en espacio mítico originario. Una suerte de territorio transustanciado, con la erección del santuario como un monumento para ser visto y reconocido de manera obligatoria en el paisaje, un lugar que a la vez rememora un acto santo y posibilita la doble experimentación del tiempo actual como tiempo de la historia sagrada y del espacio habitual como Tierra Santa (Segato, 2008).

\section{Conclusión}

En el contexto de la nueva política espacial, ahora son los grupos sociales los que producen y recrean el territorio. Así pareciera resultar para el grupo particular de los habitantes de los municipios de Choachí y de Ubaque que procuran despertar el territorio, una propuesta que se erige como necesidad para reafirmar la tradición muisca y asegurar de esta manera una identidad de carácter ancestral por fuera de la definición jurídico - estatal de lo étnico. En este sentido, la construcción de una narrativa compartida vuelve sobre el territorio para posibilitar la comunión interior del grupo: la producción de una memoria, que no abandona la fascinación por lo ancestral y lo milenario, se erige como una denuncia ante el deterioro ambiental. Lo que se considera como una posibilidad 
en la reactualización de una tradición se convierte ahora en la tradición que es propia, por cuanto a la sensación de indescifrabilidad que refleja la inexistencia clara de contenidos unívocos del pasado de una cosmogonía muisca se superpone la capacidad de los buscadores espirituales por recrear el territorio a través del páramo y la laguna, que toman la forma de monumentos sobre los que se vuelve una y otra vez para escenificar el principio holístico. "Pedir permiso a la Madre Tierra" para que faculte al mediador a convocar nuevas firmas de la ley de origen es tan solo un ejemplo de esto último.

Pero en las apreciaciones de lo institucional católico no son menos sugerentes las voces de cercanía con respecto a lo ancestral, un rastro necesario para responder en qué momento dejamos de ser lo que éramos, pero también suspensión momentánea de una única salvación en el Dios católico. Si bien se comparte la necesidad de volver sobre la naturaleza con el ánimo de alentar una pastoral ecológica como garantía de un mundo mejor, la lectura de la devoción mariana como rasgo que impregna una particularidad sobre el territorio es ya la garantía de una primacía de la religión católica sobre lo que haya sido y siga siendo la tradición muisca.

Pensar, entonces, en la reconfiguración de lo religioso en el mundo contemporáneo es percibir las distintas formas de producción de lo sagrado, lo trascedente y lo espiritual, que se comparten, por lo menos para los casos estudiados, entre la Iglesia católica y los buscadores espirituales. En este sentido, adjudicar usos exclusivos de religiosidad a un único grupo (por ejemplo, estableciendo una unidireccionalidad entre los buscadores y los repertorios new age) sería desconocer la libertad de contagio de los diferentes agentes religiosos en el contexto de una amplia circulación de creencias que escapan a un control centralizador, tal y como se enunció en la intención de los representantes del clero.

\section{Referencias}

Arquidiócesis de Bogotá (2006). Novena a Nuestra Señora de Belén, patrona de Ubaque. Bogotá, Colombia: Autor.

Arquidiócesis de Bogotá (29 de septiembre de 2017). Visita al Santuario de Nuestra Señora de Belén de Ubaque [Video]. Recuperado de https://www.youtube.com/ watch?v=9efug_Wlj3Q

Carozzi, M. J. (2006). Otras religiones, otras políticas: algunas relaciones entre movimientos sociales y religiones sin organización central. Ciencias Sociales y Religión, 8(8), 11-29. Recuperado de https://doi.org/10.22456/1982-2650.2290 
Ceriani Cernadas, C. (2013). Diversidad religiosa y pluralismo espiritual: notas para repensar las categorías y sus dinámicas de producción. Corpus: Archivos virtuales de la alteridad americana, 3(2). https://journals.openedition.org/corpusarchivos/582

Certeau, M. (2010). La invención de lo cotidiano. Tomo 1: Artes de hacer. Ciudad de México, México: Universidad Iberoamericana.

Club Los Pumas de Ubaque (29 de septiembre de 2017). Caminata Bogotá Ubaque - Santuario Virgen de Belén. Recuperado de https://www.youtube.com/ watch?v=Z63GLOxjq2s

Cruz Esquivel, J. y Mallimaci, F. (2017). Religión, medioambiente y desarrollo sustentable: la integralidad en la cosmología católica. Revista de Estudios Sociales, 60, 72-86. http://dx.doi.org/10.7440/res60.2017.06

De la Torre, R. (2013a). La religiosidad popular: encrucijadas de las nuevas formas de la religiosidad contemporánea y la tradición (el caso de México). Ponto Urbe, 12(1). Recuperado de https://journals.openedition.org/pontourbe/581

De la Torre, R. (2013b). Religiosidades indo y afroamericanas y circuitos de espiritualidad new age. En R. de la Torre, C. Gutiérrez Zúñiga y N. Juárez Huet (eds.), Variaciones y apropiaciones latinoamericanas del new age (pp. 27-46). México: El Colegio de Jalisco.

Gaitán Guaje, S. E. (2016). Nuestra Señora de Belén de Bochica: jeques, amancebados y vida cristiana en el valle de Ubaque, siglos XVI y XVII (Tesis de maestría). Universidad Nacional de Colombia, Bogotá, Colombia. Recuperado de http://www.bdigital. unal.edu.co/52300/

Gamboa, J. A. (2015). Los muiscas y su incorporación a la monarquía castellana en el siglo XVI: nuevas lecturas desde la Nueva Historia de la Conquista. Tunja, Colombia: Universidad Pedagógica y Tecnológica de Colombia.

Gómez Montañez, P. F. (2009). Los chyquys de la nación muisca chibcha: ritualidad, resignificación y memoria. Bogotá, Colombia: Universidad de los Andes.

Gutiérrez Zúñiga, C. y De la Torre, R. (2013). Introducción. En R. de la Torre, C. Gutiérrez Zúñiga y N. Juárez Huet (eds.), Variaciones y apropiaciones latinoamericanas del new age (pp. 13-26). Ciudad de México, México: El Colegio de Jalisco.

Henao Neuta, D. F. (2016). Muiscas de Bosa: memoria oral, raizal y territorial (Tesis de grado). Universidad Nacional de Colombia, Bogotá, Colombia.

Hervieu-Léger, D. (2005). La religión, hilo de memoria. Madrid, España: Herder.

Hoffmann, O. (2016). Divergencias construidas, convergencias por construir: identidad, territorio y gobierno en la ruralidad colombiana. Revista Colombiana de Antropología, 52(1), 17-39. https://doi.org/10.22380/2539472X1

La caminata de la Virgen. (1998). Expresión de Oriente, p. 7.

Lozano Velásquez, F. (2009). Prólogo. En F. Lozano Velásquez y J. G. Ferro Medina (eds.), Las configuraciones de los territorios rurales en el siglo XXI (pp. 23-34). Bogotá, Colombia: Pontificia Universidad Javeriana. 
Mançano, B. (2009). Territorio, teoría y política. En F. Lozano Velásquez y J. G. Ferro Medina (eds.), Las configuraciones de los territorios rurales en el siglo XXI (pp. 35-62). Bogotá, Colombia: Pontificia Universidad Javeriana.

Martínez, G. (1995). Catorce años menos. Expresión de Oriente, p. 6.

Meza, C. A. (2008). Urbanización, conservación y ruralidad en los cerros orientales de Bogotá. Revista Colombiana de Antropología, 44(2), 439-480. Recuperado de https:// www.redalyc.org/pdf/1050/105012451007.pdf

Nates Cruz, B. (2011). Soportes teóricos y etnográficos sobre conceptos de territorio. Revista Co-herencia, 8(14), 209-229. Recuperado de https://dialnet.unirioja.es/descarga/articulo/4079923.pdf

Osorio, F. (2009). Recomposición de territorios en contextos de guerra: reflexiones desde el caso colombiano. En F. Lozano Velásquez y J. G. Ferro Medina (eds.), Las configuraciones de los territorios rurales en el siglo XXI (pp. 417-440). Bogotá, Colombia: Pontificia Universidad Javeriana.

Ospina, M. y Sanabria, F. (2004). Nuevas espiritualidades y recomposición institucional en la Iglesia católica: la era del laicado carismático. En A. M. Bidegain (dir.), Historia del cristianismo en Colombia: corrientes y diversidad (pp. 481-509). Bogotá, Colombia: Taurus.

Pardo Díaz, F. H. (1996). Quinientos años de historia chiguana. Bogotá, Colombia: Litoformas Modelo.

Rincón Avellaneda, M. P. (2016). Conflictos territoriales y proyectos de infraestructura vial. Bitácora Urbano-Territorial, 26(2), 71-78. Recuperado de https://dialnet. unirioja.es/servlet/articulo? codigo $=5612376$

Sarrazin, J. P. (2008a). El chamanismo es un camino: las culturas indígenas como fuente de sabiduría espiritual en Bogotá. En K. Argyriadis, R. de la Torre, C. Gutiérrez Zúñiga y A. Aguilar Ros (coords.), Raíces en movimiento: prácticas religiosas tradicionales en contextos translocales (pp. 329-362). Guadalajara, México: El Colegio de Jalisco.

Sarrazin, J. P. (2008b). La "espiritualización" de los discursos neoindígenas en Colombia. Trace: Travaux et recherches dans les Amériques du Centre, 51(1). Recuperado de https://journals.openedition.org/trace/470

Sarrazin, J. P. (2012). New age en Colombia y la búsqueda de la espiritualidad indígena. Revista Colombiana de Antropología, 48(2), 139-162. Recuperado de https:// www.redalyc.org/html/1050/105026884007/

Segato, R. L. (2008). La faccionalziación de la república y el paisaje religioso como índice de una nueva territorialidad. En A. Alonso (comp.), América Latina y el Caribe: territorios religiosos y desafíos para el diálogo (pp. 41-86). Buenos Aires, Argentina: Consejo Latinoamericano de Ciencias Sociales. Recuperado de http:// biblioteca.clacso.edu.ar/clacso/gt/20150115051526/territorios_religiosos.pdf

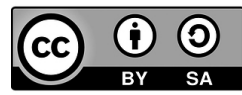

